\title{
LA EXPRESIÓN ME JODÉS/ JODEME (QUE) EN ESPAÑOL RIOPLATENSE Y LA NOCIÓN DE MIRATIVIDAD
}

\author{
Laura Kornfeld \\ Universidad de Buenos Aires \\ Consejo Nacional de Investigaciones Científicas y Técnicas \\ laura_malena@yahoo.com.ar
}

Resumen: Este trabajo se propone analizar las propiedades gramaticales de una expresión relativamente novedosa del español rioplatense: jodeme/ me jodés (que). En ambas variantes, el significado que aporta la expresión es de sorpresa enfática ante cierto evento. Corresponde al registro coloquial y oral, con mayor frecuencia entre los jóvenes. Primero presentamos algunas notas sobre las propiedades gramaticales y semánticas del verbo léxico joder, para luego centrarnos en las de jodeme/ me jodés (que) y en los procesos que involucran su cristalización y ulterior gramaticalización. Luego comparamos el caso de me jodés/ jodeme (que) con otras estructuras del español de la Argentina que expresan la sorpresa enfática, como no va que y la construcción de la región guaranítica habia sido (que) (cfr. Avellana, 2012).

Palabras clave: Gramaticalización, Sorpresa, Modalidad, Miratividad, Español de la Argentina

\begin{abstract}
The present paper intends to analyze the grammatical properties of a (relatively) new expression in Río de la Plata Spanish: jodeme/ me jodés (que). In both variants the meaning expressed is emphatic surprise facing an event. It belongs to colloquial and oral registers and is more frequent among young people. We expose some notes about the grammatical and semantic properties of the lexical verb joder, in order to focus on the properties of jodemel me jodés (que) and on the processes concerning its crystallization and subsequent grammaticalization. We also compare the case of me jodés/ jodeme (que) with other structures of Argentinian Spanish also expressing emphatic surprise, such as no va que and babia sido (que) in Spanish in contact with Guaraní (cf. Avellana, 2012).
\end{abstract}

Keywords: Grammaticalization, Surprise, Modality, Mirativity, Argentinian Spanish 


\section{Introducción}

El presente trabajo se propone analizar las propiedades gramaticales de una expresión relativamente novedosa del español rioplatense, que cuenta con dos variantes virtualmente sinónimas. En ambas aparece el verbo joder en segunda persona singular y un clítico de primera singular, con las variantes en indicativo (1.a) o imperativo (1.b):

(1) a. ¡Me jodés que el ingeniero calculó mal el Paseo del Bajo y los camiones no pasan!

b. Jodeme que el gobierno sacó un nuevo bono que se llama BOTE.

En las dos variantes, el significado que aporta la expresión es de sorpresa enfática ante cierto evento. Se registra en español rioplatense (Argentina, Uruguay, con extensiones en Paraguay), y corresponde, en particular, al registro coloquial y oral, con mayor frecuencia entre los jóvenes. ${ }^{1}$

Con el fin de desarrollar un análisis de esta expresión en sus dos variantes, primero presentamos algunas notas mínimas sobre el significado y la gramática del verbo léxico joder. Luego nos centramos en jodeme/ me jodés (que), con el fin de establecer las propiedades gramaticales y semánticas de las oraciones en las

\footnotetext{
${ }^{1}$ La mayor parte de los datos que se discutirán en el trabajo son parte de la oralidad secundaria y han sido recopilados sobre todo de Twitter, aunque algunos surgen de búsquedas generales en Google. Se han adaptado (mínimamente) en ortografía. Solo son ejemplos construidos algunos paradigmas puntuales (como 5-10, 14-16) y los datos agramaticales en general.
} 
que intervienen y de caracterizar, en particular, los procesos que involucran su cristalización y ulterior gramaticalización.

Por último, comparamos el caso de me jodés/ jodeme que con otras estructuras del español de la Argentina que también expresan la sorpresa enfática, que incluyen al marcador rioplatense no va que y a la construcción propia de la región guaranítica habia sido (que) (cfr. Avellana, 2012; Avellana y Carol, 2019). De este modo, siguiendo las líneas de dos trabajos previos (Kornfeld, 2018, 2019), esperamos establecer las propiedades de jodeme / me jodés (que) para contribuir al inventario de las expresiones ligadas con la miratividad en tanto noción translingüística (cfr. Aikhenvald, 2012, entre otros), en particular, en el español de la Argentina.

\section{Notas sobre el verbo léxico joder}

Joder es un verbo clásico y representativo del español rioplatense, también muy usado en otras variedades del español. Según el Diccionario de la lengua española de la Real Academia, se trata de un verbo malsonante y polisémico, cuyas definiciones más generales compartimos en la Argentina: 'destrozar, arruinar o echar a perder algo', con las variantes transitiva (2.a) e inacusativa (2.b), de la cual surge el muy usado participio jodido con el copulativo estar' (2.c), y 'molestar, fastidiar', como en (3).

\footnotetext{
${ }^{2}$ En la Argentina, debe diferenciarse este significado del que aparece cuando el participio acompaña el verbo copulativo ser referido a personas: 'ser (una) mala persona, malévolo'
} 
(2) a. Ese laburo le jodió la salud.

b. Se le jodió la salud.

c. Y, con esto de la pandemia, los pequeños comerciantes están jodidos...

(3) a. Una más y no jodemos más...

b. Niño, deja ya de joder con la pelota...

De las definiciones generales se derivan fácilmente algunas definiciones bien arraigadas en la Argentina (compartidas con diferentes países cercanos, sobre todo Uruguay). Así, joder puede emplearse con los significados de 'engañar', 'estafar' (4.a), 'cargar' (en el sentido rioplatense) o 'burlar' (4.b), así como en una variante intransitiva como 'divertirse' (4.c) (derivada tal vez de (4.b) o incluso de (3)).

(4) a. Y así el sapo lo jodió al zorro.

b. Me estuvo jodiendo con la maestra.

c. Ayer salimos a joder por ahí.

d. Esto es una joda.

Entre las definiciones de (4.b) y (4.c) se reparte la interpretación del nombre joda como 'cargada, broma, diversión' (de hecho, (4.d) es ambigua entre esos significados), con las correspondientes expresiones cristalizadas: en joda ('en broma'), de joda ('de parranda'), joda loca ('gran parranda', muchas veces usada irónicamente), estar en la joda ('no tomarse las cosas en

(Juan es jodido/ es un jodido). Si se aplica a situaciones, en cambio, el significado de jodido se equipara a 'difícil' con ambos verbos copulativos. 
serio'; 'no trabajar o no estudiar'; 'salir mucho'; 'tomar o drogarse', según definiciones específicas).

En cambio, al igual que en la mayoría de los países hispanoamericanos, joder no se usa con el significado etimológico de 'fornicar', salvo lúdica o irónicamente, por el contacto con las traducciones o doblajes de otras variedades, en particular la peninsular. Tampoco existen (en la Argentina y en la mayor parte de América) algunas de las interjecciones y frases hechas propias del español peninsular (e.g, iJoder! o ¡Hay que joderse! mientras que Jodete no significa 'Muérete/ Púdrete'), que se derivan de esa definición. Por esa causa, joder no es un verbo tan "malsonante" o "vulgar" en Argentina, sino, en todo caso, (muy) coloquial e informal.

$\mathrm{Si}$ analizamos el abanico de significados de joder, encontraremos, entonces, dos conjuntos distintos, que básicamente coinciden con los usos generales en oposición a los (exclusivamente) rioplatenses. El primero está conformado por las definiciones de 'arruinar', 'perjudicar', 'molestar' o 'fastidiar' (cfr. (2) y (3)). Dado que pueden tener variantes pronominales inacusativas, como en (2.c), con el significado de 'perjudicarse' o 'arruinarse', joder puede ser considerado como un verbo causativo en esos usos.

El otro conjunto de significados ('engañar', 'estafar', 'burlar', dejando de lado el caso de 'divertirse' en (4.c), una variante únicamente intransitiva) se corresponde básicamente con los llamados "verbos de relaciones humanas" como engañar, felicitar y traicionar. Se trata de verbos de dos argumentos, ambos humanos ('alguien $\mathrm{V}$ a alguien' es la valencia argumental). 
Pujalte y Zdrojewski (2013) proponen una serie de pruebas de reconocimiento de las propiedades de esta clase de verbos, al ocuparse específicamente del caso de los verbos inergativos transitivizados en el español rioplatense, que terminan transformados justamente en verbos de relaciones humanas (e.g., lo vaciló, lo madrugó, lo durmió, lo acostô). Aplicaremos esas pruebas a joder con la definición de 'burlar', que es la que parece en juego en los datos iniciales de (1).

Por un lado, notemos que, de acuerdo con Pujalte y Zdrojewski, los verbos de relaciones humanas tienen sujetos necesariamente agentivos, nunca causativos. Así se advierte en la imposibilidad de aplicarles una paráfrasis causativa a su significado (cfr. (5)) o de que el sujeto tenga una interpretación no humana (cfr. (6)), como ilustramos con joder y el caso más canónico de estafar.

(5) a. Juan (lo) jodió a Jorge $\neq$ Juan hizo joder(se) a Jorge.

b. Juan (lo) estafó a Jorge $\neq$ Juan hizo estafar(se) a Jorge.

(6) a. Juan/*el viento jodió a María. (agente /*causa)

b. Juan/*el viento estafó a María. (agente /*causa)

Asimismo, los tipos de se que coaparecen con joder (con el sentido relevante) son consecuentes con esta caracterización: por un lado, el verbo es incompatible con el se anticausativo (5), ya que el evento no puede recibir una interpretación de proceso espontáneo (7). Por otro lado, sí puede combinarse con el se impersonal, que remite, justamente, a su interpretación agentiva (8): 
(7) a. Juan jodió al vecino. $\rightarrow$ *el vecino se jodió.

b. Juan estafó al vecino. $\rightarrow$ *el vecino se estafó.

(8) a. A Pedro se lo jode con facilidad.

b. A Pedro se lo estafa con facilidad.

Los datos previos muestran un contraste claro entre las propiedades de los verbos de relaciones humanas y los que tendrían los verbos causativos, que admitirían la paráfrasis de (5) (e.g., Juan bizo fastidiar(se) a Pedro), la interpretación de (6) (La lluvia fastidia a María) y el se anticausativo de (7) (María se fastidiô).

En cuanto a las propiedades del objeto del verbo, el argumento interno de los verbos de relaciones humanas también tendrá (necesariamente) interpretación humana y, por lo tanto, el OD recibirá la $a$ de acusativo. Pujalte y Zdrojewski observan que esos verbos no son compatibles con la construcción resultativa de estar + participio, que se aplica al objeto al omitir el agente (9), ni con los predicativos objetivos (10), que funcionan como predicación secundaria y, por lo tanto, también aluden a un estado resultante:

(9) a. Juan lo jodió a Pedro. $\rightarrow$ *Pedro está jodido ${ }^{3}$

b. Juan estafó a Pedro. $\rightarrow *$ Pedro está estafado.

$$
\begin{aligned}
& \text { a. A Pedro lo jodieron *asustado. } \\
& \text { b. A Juan lo estafaron *dormido. }
\end{aligned}
$$

En suma, joder (al igual que sus cuasisinónimos burlar, cargar, embromar, estafar, engañar) es un verbo transitivo y el argumento

\footnotetext{
${ }^{3}$ Es agramatical con el significado relevante, no lo sería con joder como 'arruinar'.
} 
interno (que va marcado en acusativo) debe referir a una entidad humana. En particular, no es compatible con un argumento directo proposicional, al revés de lo que ocurre con verbos "de decir" o "de sentimiento" (e.g., Dijo / Siente que ni la mirás), tal como ampliaremos en el apartado $4 .{ }^{4}$ Por eso, si aparece algún modificador con valor eventivo o proposicional, tendrá estatuto de adjunto causal dentro del SV, y debería ser introducido por una preposición no seleccionada (i.e., con en los ejemplos de (11)):

(11) a. Me jodió con la llegada de mi prima.

b. Me jodió con que me iba a dejar tirado en la ruta.

\section{Distribución sintáctica}

Una serie de contextos pragmáticos parecen oficiar como pasos necesarios para dar cuenta de cómo surgen jodeme/ me jodés (que) en datos del español rioplatense como los iniciales de (1). Entre ellos podemos mencionar contextos ligados con la modalidad exhortativa o volitiva que involucran a joder, con el significado relevante de 'burlar' (aunque pueda recibir, ambiguamente, la interpretación de 'molestar'). Si nos centramos en las variantes transitivas, veremos que se admiten diferentes combinaciones de persona y número en la forma verbal y el clítico, aunque nos interesa en particular focalizar la que veíamos en los ejemplos iniciales de (1): forma verbal en

\footnotetext{
${ }^{4}$ En cambio, la definición del español general de 'molestar, fastidiar', ilustrada en (3), sí admite una variante con una proposición completiva, como ocurre con Me jode que no me babla, con la claúsula encabezada por que como sujeto de la oración.
} 
segunda persona del singular, clítico en primera persona del singular.

Así, por ejemplo, encontramos las formas imperativas, dentro de las cuales la más usada es la combinada con la negación, que admite adjuntos causales dentro del SV, encabezados por la preposición con, como los ya vistos en (11) (cfr. 12.a-b). Aquí las oraciones son parafraseables como 'No me embromes/ burles/ cargues', con valores semántico-pragmáticos de sugerencia, pedido u orden, y, marginalmente, como expresiones de repudio o incluso amenaza, como en (12.c), en que se ilustra el caso en que aparece un adjunto causal encabezado por que, que no modifica al SV sino a la oración en su conjunto (i.e., se lee como 'No me jodas porque te voy a matar'): ${ }^{5}$

(12) a. No me jodas con ese tema, que es algo serio.

b. No me jodas con que no me la banco porque no es gracioso.

c. No me jodas, que te voy a matar.

A causa del propio significado de joder, la forma del imperativo positivo es infrecuente en la combinación del verbo con el clítico en primera persona del singular y suele interpretarse irónicamente (cfr. (13.a-c)). Tal como hemos visto en (12.c), puede aparecer una subordinada encabezada por que (y precedida o no por coma), con un claro matiz causal (i.e.,

\footnotetext{
${ }^{5}$ Si bien focalizamos la combinación de categorías morfológicas que nos interesa en función de nuestros datos iniciales de (1), vale recordar que es posible emular los ejemplos anteriores variando la flexión asociada al verbo (i.a), al clítico (i.b) o a ambos (i.c):

(i) a. No me joda / jodan más, que estoy de mal humor.

b. No lo / nos jodas más.

c. No lo jodan / jodamos más.
} 
'porque') sobre la oración en su conjunto (13.b). En cambio, resulta mucho más productiva con otras variantes morfológicas, sea en el verbo (13.c) sea en el clítico (13.d), y con otras clases de objetos (13.e), con valores semántico-pragmáticos de sugerencia, pedido u orden:

(13) a. Jodeme (nomás) con el rubio.

b. Jodeme (,) que me gusta/ que no me molesta.

c. Jodame/ jodanme nomás.

d. Jodelo/ jodelas y fijate cómo reacciona(n).

e. Jodamos al boludo ese...

Otros contextos dialógicos relevantes pueden ser vinculados con la modalidad exhortativa, tanto en enunciados imperativos como en interrogativos. Muestran cierto grado de cristalización las combinaciones con la primera y la segunda persona, siempre con el significado relevante de 'burlar' (i.e. las variantes de B (cfr. (14.b)) también podrían ser ¿Lo estás diciendo en joda?, ¿Es una joda?, ¿Es un chiste?):

(14) A: -No quiero ir a la fiesta.

B: -¿Me jodés? / ¿Me estás jodiendo? (más frecuente)

A: -Sí, te estaba jodiendo, boludo.

(15) A: -Aumentaron los sueldos el 300\%.

B: -No me jodas, boludo.

Los contextos semántico-pragmáticos de (12-15) son el verdadero punto de partida para nuestra indagación. En (16), reproducimos toda una serie de variantes imperativas e 
indicativas que utilizan joder (siempre partiendo del significado de 'burlar') y que aparecen como respuestas autónomas en contextos dialógicos:

(16) A: -Los nuevos bonos del gobierno se llaman BOTES

B: - ¡No me jodas!

C: -¿Me jodés?

D: -No, me jodés!

E: -jodeme!

Todas las variantes de (16) denotan sorpresa e incredulidad ante una información (relativamente) nueva para el hablante. En la más conservadora (B), aparece el imperativo negado, en forma semejante a lo que habíamos señalado para los datos de (12) y (15), pero con cierto grado de cristalización pragmática. En efecto, en (15) esa respuesta con el imperativo negado supone (más) literalmente desconfianza o incredulidad hacia los dichos del interlocutor, pero luego se cristaliza como expresión pura de la sorpresa o la admiración (sin que medie en absoluto la desconfianza), tal como se verifica en B. La respuesta de C implica una pregunta con indicativo, no ya con el valor "literal" de la perífrasis progresiva (como en 14), sino como marca exclusiva de sorpresa. Aun con cierto grado de cristalización en una suerte de puesta en escena de la "incredulidad fingida", ambas respuestas son esperables y largamente más extendidas entre los hablantes del español rioplatense coloquial.

Por su parte, la respuesta de D muestra una profundización de esa dirección, al transformar la pregunta de $\mathrm{C}$ en fragmento admirativo, acentuando así la expresión de la sorpresa. La 
respuesta de E, todavía más novedosa, probablemente suponga en su origen algún grado de ironía, ya que es exactamente contraria a las expresiones más previsibles de B-C: el imperativo aparece como positivo (en lugar de negativo). Así, de una interpretación que literalmente implicaría un pedido o una orden (cfr. (12)), el verbo joder pasa a condensar los valores modales de sorpresa que mencionábamos en un inicio en un verdadero abanico de respuestas con diferente entonación y rasgos gramaticales asociados.

A partir de las dos últimas respuestas en (16), D y E, se han derivado en los últimos años los usos de jodeme/ me jodés que en nuestros ejemplos iniciales de (1), que suponen una extensión significativa de (16) como marca de sorpresa admirativa, a menudo usada con ironía ante un hecho patentemente verdadero (17.c) o patentemente falso (17.f):

(17) a. ¡Me jodés que el ingeniero calculó mal el Paseo del Bajo y los camiones no pasan!

b. Me jodés que reapareció la señora Bisman.

c. Me jodés que 'piscuí' es inglés y no lunfardo...

d. Jodeme que el gobierno sacó un nuevo bono que se llama BOTE.

e. "Jodeme que la propia Armada Argentina puso 'se hundió"”, se lamentó un usuario.

f. Jodeme que van a demoler los 3000 jardines de infantes que hizo Macri con la plata que iba a Fútbol para Todos???!!! 
En los ejemplos de (17) se agrega la conjunción que, que habilita la aparición de una (aparente) cláusula subordinada de carácter completivo (en el apartado 4 discutiremos la naturaleza de esa cláusula). Ante el hecho descripto en la cláusula completiva (que puede o no tener una valoración negativa), reacciona el hablante con sorpresa. En este contexto, solo se admiten las variantes flexivas que ya hemos destacado para el verbo joder: tiempo presente del indicativo o imperativo, en segunda persona singular de confianza; en el caso del clítico, solo me, ubicado en la posición de proclítico o enclítico según le corresponda.

Los hablantes pronuncian estas oraciones con diversas entonaciones (interrogativa o exclamativa, más raramente suspendida), como se puede ver por los signos escritos fluctuantes que utilizan.

Es habitual que aparezcan otras marcas pragmáticas de la sorpresa enfática, como la acumulación de signos de interrogación y/ o exclamación (cfr. varios ejemplos de arriba) y también partículas como $\mathrm{Naa}$ o jaa, que pueden ligarse con el origen que hipotetizábamos a partir de los ejemplos de (16) y con la puesta en escena de una incredulidad fingida:

(18) a. Naa, me jodés que le cortan la cabeza...

b. Jodeme que sos vendedor de planes... naaaaaaaa

c. Jodeme que había dejado la joda, jaaaa.

d. Jodeme que ustedes también tienen uno que gime mientras juega?! Ajajajja 
En cuanto a las diferencias entre jodeme que y me jodés que, hemos dicho que no se constata ninguna respecto de su semántica. Debe destacarse, sin embargo, que la forma del imperativo es un poco más ambigua en los discursos escritos (incluyendo la oralidad secundaria, que es la fuente de nuestros datos, cfr. nota al pie 1), donde a veces se hace necesario releer la oración para ratificar qué interpretación asignarle a la expresión. Así, en las siguientes oraciones, la interpretación de la cláusula encabezada por que es la de adjunto causal que señalábamos en (12.c), y no la de (17.d-f) o (18.b-d):

(19) a. "Cuando empezamos a trabajar ella me dijo 'Mirá, Miguel, cargame todo lo que quieras, jodeme que no me molesta para nada"”

b. Jodeme que me muero muerto... clarin.com mintió?

Es decir, (19) no expresa sorpresa, sino que remite al significado léxico original de joder ('burlarse'). La ambigüedad ilustrada no se da nunca con me jodés que, lo que tal vez explique la mayor frecuencia relativa de esa variante como marcador de sorpresa. ${ }^{6}$

Si analizamos ahora las propiedades gramaticales internas de la cláusula subordinada, veremos que el verbo puede tener todas las personas del paradigma y aparecer en todos los tiempos del indicativo: presente, futuro o pasado (con aspecto perfectivo o imperfectivo, cfr. (20.b-c)).

\footnotetext{
${ }^{6}$ En efecto, encontramos más páginas de resultados de Google para me jodés que, aunque no se trata de una diferencia taxativa (y puede que dependa más bien del procedimiento de búsqueda de datos).
} 
(20) a. Jodeme que te había pagado/ paga/ pagó/ pagaba/ va a pagar en negro.

b. Me jodés que tenían a Lombardi, Yanco y Avruj como intelectuales.

c. Me jodés que tuviste todo ese quilombo con HNK.

En cambio, es raro en condicional (21.a) e imposible en subjuntivo (21.b).

(21) a. ??Me jodés que te pagaría en negro.

b. *Me jodés que te pague/ pagara/ haya pagado/ hubiera pagado en negro.

Este predominio absoluto del indicativo no parece ser una "mera formalidad". En todos los casos, el evento que se describe en la proposición encabezada por que sistemáticamente se da por cierto y comprobado; ante ese hecho es que el hablante expresa su marcada sorpresa. Esa es una propiedad muy significativa en relación con la semántica-pragmática de la construcción, ya que involucra un valor epistémico, que se suma al evaluativo de sorpresa, tal como discutiremos en detalle en los próximos apartados.

Si continuamos analizando las propiedades gramaticales de la cláusula subordinada, vemos que presenta compatibilidad con diversas perífrasis temporales (22), aspectuales (23) y modales, tanto epistémicas (24), como deónticas (25), siempre que el auxiliar tenga modo indicativo, como ya señalamos:

(22) a. Me jodés que van a continuar con las publicaciones acá! 
b. ah, jodeme que lo había sacado de "Hola, soy Germán”...

(23) a. Jodeme que están haciendo una fiesta por unos portones...?

b. Me jodés que seguís encarando por ahí, maestro?

c. ¡¡Hace un mes! Me jodés que recién hoy me estás contando.

(24) a. "Me jodés que podés criticar a @larissariquelme".

b. Jodeme que puede pasarle eso a la oreja de un adulto.

(25) a. Jodeme que te tienen que invitar para poder jugar a algo que tendría que ser gratis.

b. me jodés que hay que conseguirle entradas a los familiares.

Además, en la cláusula completiva también puede aparecer la negación, a veces con una particular interpretación semántica, por ejemplo, una variable modal (cfr., por ejemplo, (26.b)).

(26) a. Me jodés que no lo pudo VAR

b. Jodeme que no vivís con 400.000 ?!

c. ¿Jodeme que no cobró este penal?

En la cláusula encabezada por que también pueden aparecer distintas clases de estructura argumental y aspecto léxico (o Aktionsart). De hecho, jodeme/ me jodés que es compatible con cláusulas completivas con verbos que representen todas las variantes aspectuales: estados (27), logros (28), actividades (29) y realizaciones (30), lo cual a su vez incluye distintos tipos de 
verbos: copulativos (27.a-b) e impersonales (27.c), inacusativos (28), inergativos (29), transitivos (30.a-b), incluyendo ditransitivos (30.c-d):

(27) a. Me jodés que el asado es un bicho muerto, asesinado y descuartizado!!

b. Jodeme que estos son mis padres.

c. me jodés que en feisbuk hay un grupo de venta de repuestos de motos...

(28) a. Me jodés que ya salió la 4ta temporada?

b. Me jodés que no te apareció en la AFIP para tildar el envío?!

(29) a. Me jodés que se va a ir a jugar a la B.

b. Jodeme que estos hincharon por Bolivia en la Copa.

(30) a. Jodeme que este tipo dijo que Dios lo hizo profeta y cobra mil pesos por el alcohol en gel.

b. Jodeme que cobró penal.

c. Jodeme que le vendimos armas al ISIS.

d. Jodeme que me estás pidiendo que te devuelva lo que me regalaste.

En suma, las cláusulas completivas de me jodés/ jodeme no presentan ninguna restricción léxico-aspectual o argumental ni en relación con la combinación del verbo con tiempos, aspectos o perífrasis modales, pero sí en cuanto al modo morfológico (i.e., puede aparecer exclusivamente el indicativo). 


\section{Sobre la gramaticalización}

En este apartado, a partir de la información recopilada previamente, nos proponemos (re) analizar las propiedades semánticas y gramaticales de la expresión jodeme/ me jodés (que). En el apartado 2 mostramos que, para decodificar el origen de esa expresión en el español del Río de la Plata, hay que partir de un significado léxico relevante de joder ('burlar') que es propio de un "verbo de relación humana", que como tal selecciona dos argumentos de interpretación humana (i.e., 'alguien $\mathrm{V}$ a alguien'). Sin embargo, a diferencia de los datos de jodeme/ me jodés que repetidos en (31), los verbos de relaciones humanas canónicos, como estafar o cargar, no aceptan nunca proposiciones completivas como argumento interno (excepto que se puedan reinterpretar como adjuntos causales, como ya vimos para el propio joder en (12.c) y (19)).

(31) a. Jodeme que no vivís con 400.000?!

b. Me jodés que cobró penal.

c. Jodeme que le vendimos armas al ISIS.

(32) a. *Estafame que es fácil comprar con la tarjeta de crédito.

b. *Cargame que la maestra de mis hijos me mira demasiado.

c. *Embromame que la música más linda es el reggaeton.

No solo no existen las proposiciones subordinadas del tipo de (32), sino que son literalmente ininterpretables, puesto que, 
como se señaló, los verbos de relaciones humanas requieren que tanto el sujeto como el objeto tengan interpretación humana (que no se puede asignar a una proposición completiva).

Un problema adicional (no menor) que causan las estructuras de (31) es que no queda claro qué función sintáctica cumpliría allí la proposición encabezada por que ni tampoco qué caso recibiría. Recordemos que, si nos guiamos por lo que ocurre normalmente en los verbos de relaciones humanas, me debería ser un objeto directo acusativo, tanto en jodeme como en me jodés.

Por lo demás, ya hemos señalado que la pérdida del significado léxico de joder en las dos variantes (imperativo o indicativo) es clara, ya que de hecho se invierte la interpretación esperable. El significado original de desconfianza hacia los dichos del interlocutor muta en sorpresa ante un hecho que se da (indudablemente) por cierto (cfr. 16). De este modo, el significado de 'burlar' se desdibuja, lo que se completa desde el punto de vista formal con la aparición de la forma positiva del imperativo y con el cambio entonativo de la forma de indicativo, como se estableció en el apartado $3^{7}$

\footnotetext{
${ }^{7}$ Notemos, a modo de paréntesis, que un proceso semejante puede atribuirse a otra expresión análoga del español del Río de la Plata, no te la puedo creer. empieza indicando literalmente desconfianza, incredulidad o descreimiento (cfr. i.a), pero, a medida que se afianza como respuesta cristalizada, expresa una sorpresa enfática que implica, paradójicamente, la plena aceptación del evento en cuestión (cfr. i.b), para luego pasar a tomar como argumento una cláusula completiva (cfr. i.c):

(i) a. A: -Se me rompió el auto.

B: -Esa excusa no te la puedo creer.

b. A: -Se murió Pepito.

B: -No te la puedo creer...
} 
A partir de los datos anteriores, queda claro que joder ya no puede ser interpretado como un verbo de relación humana en me jodés/ jodeme que. Una alternativa razonable es que se haya relexicalizado, adquiriendo una nueva definición. Por ejemplo, podría haberse transformado en un verbo de sentimiento, como son canónicamente alegrar, entristecer o preocupar. Esa posibilidad se ve sostenida por el hecho de que paráfrasis factibles para jodeme/ me jodés que en (31) son 'me sorprende/ me asombra/ me maravilla/ me indigna / me subvierte (que)', todos verbos de sentimiento, como muestra (33). Adicionalmente, las cláusulas subordinadas en esos verbos denotan un evento que se presupone verdadero, es decir que hay una coincidencia desde el punto de vista epistémico con lo que notábamos en el apartado 3:

a. Me sorprende/ preocupa que no vivas con 400000 pesos.

c. No te la puedo creer que encontré una foto así.

En (i.c) el la es completamente expletivo, ya que la proposición completiva es ahora el OD. Otra prueba de la gramaticalización es que la cláusula completiva suele tener el verbo en indicativo (ii), aunque aún se encuentra alternancia (menos frecuente) con subjuntivo (cfr. iii), al contrario de los consistentes datos que encontramos para me jodés/jodeme que (cfr. 21, en particular).

(ii) a. No te la puedo creer que ya estamos en noviembre.

b. No te la puedo creer que suspendieron la del segundo semestre por este clima.

(iii) a. No te la puedo creer que haya perdido así.

b. No te la puedo creer que sean tan copiones.

8 Adicionalmente, recordemos que una de las definiciones del español general para joder es indudablemente como verbo de sentimiento: 'molestar', 'fastidiar' (cfr. ejemplos iniciales de (3)). 
b. Me asombra/ entristece que haya cobrado penal.

Sin embargo, esta solución no carece de problemas. Por una parte, tal como ilustra (33), con los verbos de sentimiento el verbo de la cláusula completiva debe ir en subjuntivo, al menos en su realización canónica, ${ }^{9}$ al contrario del indicativo que hemos señalado como obligatorio para jodeme/ me jodés que (cfr., en particular, (21)).

Por otra parte, en oraciones como (33) el sujeto de la oración sería la proposición subordinada encabezada por que, con el me como objeto acusativo y el verbo en tercera persona del singular. Ese análisis no podría ser aplicado fácilmente a datos como (31), con el verbo en segunda persona del singular. En este sentido, recordemos que los verbos de sentimiento no admiten formas de segunda persona singular en imperativo (cfr. (34)) o en indicativo, independientemente de la entonación de la cláusula (cfr. (35)):

(34) a. *Sorprendeme que no vivas/ vivís con 400000 pesos.

b. *Entristeceme que haya cobrado/ cobró penal.

(35) a. *(¿)Me preocupás que no vivas/ vivís con 400000 pesos(?)

b. *(¿)Me asombrás que haya cobrado/ cobró penal(?)

Los datos de (33-35), tan contradictorios con los que advertimos para jodeme/ me jodés, nos llevan a dejar de lado la hipótesis de que joder se haya relexicalizado allí como verbo de sentimiento. Descartada esa posibilidad, otra alternativa sería

\footnotetext{
${ }^{9}$ Debemos notar, sin embargo, que se registran algunos casos con indicativo: Me sorprende que veo mucha gente en la calle; Me sorprende que el Frente de Todos habla de corrupción.
} 
que lo haya hecho como un verbo "de decir". Los verbos de decir son triádicos (como aparentemente serían jodeme y me jodés en 31) y (solo) aceptan indicativo en la proposición subordinada (cfr. (36-37)). Adicionalmente, sí admiten las categorías morfológicas relevantes en el clítico y en el verbo, sea en imperativo o indicativo, como se observa con jurary decir en esos ejemplos:

(36) a. Jurame/ Decime que vivís (*vivas) con 400000 pesos.

b. Jurame/ Decime que cobró (*haya cobrado) penal.

(37) a. ¿Me jurás que vivís (*vivas) con 400000 pesos?

b. ¿Me decís que cobró (*haya cobrado) penal?

De este modo, desde un punto de vista formal, los verbos de decir se acercarían más que los verbos de sentimiento a las propiedades gramaticales de la expresión relevadas en la sección anterior. En caso de que la relexicalización fuera factible, tendríamos una resignificación de joder como verbo de decir, que llevaría, a su vez, a una recategorización de caso: así, en (31) el acusativo de mejodés/ jodeme se debería reinterpretar como un OI dativo, para que la proposición completiva pueda ser, a su vez, el OD.

Los problemas de esa hipotética transformación son de índole semántica. Por un lado, no es evidente que joder en las dos variantes de esta expresión pueda considerarse un verbo de decir, más allá de que exista la posibilidad de paráfrasis plausibles, del estilo 'Me jodés que (decís que) no vivís con 400000 pesos/ cobró penal', para (31.a-b). Por otro lado, más significativo aún, la proposición a la que modifica me jodés/ jodeme 
siempre se asume como absolutamente verdadera. En cambio, las oraciones de (36-37), con la proposición en indicativo, no presuponen la verdad del evento en cuestión, ya que este queda subsumido al verbo de decir correspondiente.

En suma, tenemos un (completo) desajuste entre las propiedades formales de me jodés/ jodeme que en (31) y su interpretación semántica, lo que imposibilita identificar la expresión como resultado de una relexicalización de joder, sea como verbo de sentimiento, sea como verbo de decir.

Ese callejón aparentemente sin salida puede resolverse si proponemos que joder no es aquí un verbo léxico que selecciona una proposición; más aún, que la pérdida de su significado léxico no implica una relexicalización, sino una deslexicalización del verbo, esto es, un proceso ligado con la gramaticalización de la estructura. Así, me jodés/ jodeme se ubicaría en una posición periférica o dislocada como marcador de modalidad, al tiempo que la cláusula introducida por que funciona en realidad como la proposición principal de la oración. Esta alternativa les daría coherencia no solo a los datos de (31-37), sino también a los fenómenos revisados en el apartado 3 .

En efecto, más allá de la pérdida de significado léxico, hemos señalado que ambas variantes se encuentran totalmente cristalizadas en cuanto a las categorías morfológicas de verbo y clítico: solo pueden aparecer la segunda persona del singular (de confianza) en el verbo (más allá de si es indicativo o imperativo) 
y la primera persona del singular en el clítico; cualquier otra variante está vedada: ${ }^{10}$

(38) a. *Jodelo que no vivís con 400.000 pesos.

b. ${ }^{*}$ Me jodieron que cobró penal....

La cristalización de las categorías morfológicas reflejada en (38) es también compatible con un proceso de gramaticalización.

Los datos aquí revisados corroboran, en suma, la viabilidad de este análisis y nos permiten concluir que jodeme / me jodés que funcionarían como marcadores gramaticalizados de modalidad que expresan la sorpresa enfática del hablante ante el evento que se transmite en la cláusula principal (que se da por plenamente cierto desde un punto de vista epistémico). Se trataría de un modificador de modalidad "alto" o periférico que señala la evaluación subjetiva del hablante ante el hecho descripto en la oración, pero que no interviene en el contenido proposicional propiamente dicho ni en el valor de verdad del enunciado ${ }^{11}$ (igual que adverbios como Sorpresivamente/Sorprendentemente, cobró penal).

${ }^{10} \mathrm{O}$, eventualmente, puede remitir a alguno de los significados léxicos de joder, como (i) lo hace con 'molestar' (cfr. nota al pie 4):

(i) \#Me jode que cobró penal....

${ }^{11}$ En términos de Cinque y Rizzi (2016), jodeme/ me jodés que se ligaría con un Sintagma de Modo Evaluativo más “alto" que el Sintagma de Modo Epistémico, tal como se propone en Avellana (2012) y Kornfeld (2019) para las expresiones que se analizarán en el apartado 5. Aquí prescindiremos de ese tipo de análisis formal para concentrarnos en los valores semánticos y gramaticales de las expresiones (remitimos al lector interesado a la propuesta de Kornfeld 2019). 
Hasta qué punto (y cómo) se codifica la información modal en jodeme / me jodés que es, precisamente, la cuestión que discutiremos en el siguiente apartado.

\section{Los matices de la sorpresa: comparación con otras estructuras}

La sorpresa es una emoción universal, que se produce cuando un hecho de la realidad no "encaja" con el modelo mental previo de un individuo. Pese a su universalidad como emoción, no está gramaticalizada en todas las lenguas. Cuando lo está, suele subsumirse en la categoría (relativamente reciente) de miratividad, que constituye una variante de la modalidad "alta" de la oración. Aikhenvald (2012) incluye dentro de la etiqueta de miratividad un conjunto de valores semánticos vinculados entre sí: a) 'comprensión, revelación o descubrimiento súbitos', b) 'sorpresa', c) 'mente no preparada', d) 'contrario a las expectativas', e) 'información nueva'. En lenguas tipológicamente diferentes, los cinco rasgos pueden aparecer referidos al hablante, al oyente o al personaje principal de una narración, según explicita la propia Aikhenvald (2012, p. 437).

Sin embargo, algunos autores coinciden en otorgarle preeminencia al primer rasgo de Aikhenvald, 'comprensión, revelación o descubrimiento súbitos’. Mexas (2016), por ejemplo, asume que el resto de las interpretaciones ligadas a la miratividad (i.e., 'sorpresa', 'mente no preparada', 'contrario a las expectativas' e 'información nueva') se derivan secundariamente en contextos específicos. De la preeminencia de la 'comprensión 
súbita', argumentan a su vez Lau y Rooryck (2017), se deduce que la naturaleza de la miratividad será esencialmente evidencial, ya que expresa un cambio en el estado epistémico de alguno de los participantes. ${ }^{12}$

En Kornfeld (2018, 2019) se estudian contrastivamente estructuras con distintos grados de gramaticalización usadas en la Argentina y que permiten expresar la sorpresa enfática. Vale la pena recuperar aquí dos de las expresiones más gramaticalizadas que funcionan como marcadores de modalidad ubicados en una posición periférica de la oración: no va que, también propia del español rioplatense coloquial, y habia sido (que), del español en contacto con guaraní (en el Nordeste argentino y Paraguay) (cfr. Avellana, 2012): ${ }^{13}$

(39) a. Y no va que la familia del otro consigue testigos

b. Había sido (que) tenía una novia bien guardadita.

Vamos a contrastar aquí las expresiones de (39) con jodeme/ me jodés que con el fin de iluminar desde otra perspectiva sus propiedades gramaticales y semánticas, empezando por la comparación con no va que.

No va que está completamente fosilizado, ya que no admite ninguna variante flexiva y la negación tiene carácter puramente expletivo, como puede verse en (40-41). Además, en principio,

12 Tal como señalan distintos autores, sin embargo, en los marcadores de modalidad mirativa no está codificado si la evidencia es directa o indirecta, ya que esta interpretación es secundaria y dependerá directamente de las variables de tiempo y aspecto (cfr. Lau y Rooryck, 2017; Salanova y Carol, 2017; Carol y Avellana, 2019).

13 Otros recursos analizados, que no trabajaremos aquí, son las perífrasis venir a + infinitivo e ir a + infinitivo (con ciertos valores morfológicos y léxico-aspectuales) y las estructuras seudocoordinadas agarra $y \mathrm{~V}$, (no) va $y+\mathrm{V}$, viene $y+\mathrm{V}$, propias del español general. 
la cláusula principal carece de restricciones morfológicas (i.e., puede aparecer en distintas personas y números) y léxicoaspectuales: aparecen sobre todo realizaciones y logros (cfr. (40)), pero también, en menor medida, estados y actividades, tal como se ilustra en (41):

(40) a. No va que una vez que bajamos la barranca y nos sentamos al lado del río vimos salir del agua unos animalitos de lo más raros (Juan José Saer, El limonero real)

b. No va que hoy fui a la mañana a la verdulería y me encontré con Ribet, el maquinista de turno... (M. Laura Santos, Haya)

c. Si mataste fue pa' no morir, y no va que te salió tan mal / que la pena pudo más, y a tu sombra te colgás (Los somáticos, "Cumbia macabra")

(41) a. Y no va que corre y se escucha "corte" (Andrés Gallina, "La última película de Paul Ellis")

b. Y no va que le dan ganas de ayudarla cuando está en problemas.

c. Pero no va que ella no sabía quién era yo.

En Kornfeld $(2018,2019)$ afirmamos que no va que tampoco tiene restricciones respecto del tiempo, aspecto y modo de la cláusula principal. En efecto, la expresión aparece combinada con verbos en pasado y presente (con interpretación de presente histórico, como en (41.a-b)) y aspectos perfectivos (cfr. (40)) e imperfectivo (cfr. (41.c)), a lo que podemos agregar otros tiempos (incluyendo pluscuamperfecto y condicional, como "futuro del pasado", cfr. (42)) y aspectos, codificados en 
perífrasis progresivas (cfr. (43.a-b)), incoativas (cfr. (43.c)), terminativas (cfr. (43.d)) o iterativas (cfr. (43.e)):

(42) a. No va que justo hoy el abuelo cumpliría cien años.

b. No va que habíamos salido a tomar el aire fresco y lo veo parado al Rosendo contra la pare', pucho en mano.

(43) a. Y no va que el pibe con gambetas, quiebres de cintura se iba metiendo por la defensa de San Lorenzo.

b. esta tarada no va que estamos saliendo del supermercado y se le cae de adentro del spencer el acondicionador (José M. Muscari, "Cotillón”)

c. No va que empecé a buscar los trabajos on-line.

d. No va que termino de desperezarme y quién me empieza a acosar...

e. No va que volvió a aparecer el virus

La única incompatibilidad de no va que señalada por Kornfeld (2019) son las perífrasis modales epistémicas (cfr. 44.a), pero en realidad la expresión tampoco puede combinarse con los modos subjuntivo (44.b) o condicional (como en (44.c), ya que (42.a) se interpreta en realidad como temporal: 'iba a cumplir'), con las perífrasis modales deónticas (44.d) y con el tiempo futuro (44.e):

(44) a. $*$ No va que podemos usarlo / puede pasarle eso a la oreja de un adulto

b. $*$ No va que fuera/ vaya a la escuela

c. ${ }^{*}$ No va que Julia sería el amor de su vida

d. *No va que debería ir/ tiene que ir a la escuela. 
e. $*$ No va que vamos a ver a Sting.

Como ya hemos señalado, jodeme/ me jodés que solo comparte la imposibilidad de que el verbo de la cláusula principal esté en subjuntivo o condicional (cfr. (44.b-45.a) y (44.c-45.b), también (21)), ya que sí puede aparecer combinado con futuro (45.c), con perífrasis deónticas (45.d) y con perífrasis epistémicas (45.e) (cfr. también (24-25) en el apartado 3):

(45) a. $*$ Me jodés que fuera/ vaya a la escuela.

b. ??Me jodés que Julia sería el amor de su vida

c. Jodeme que vamos a ver a Sting.

d. Jodeme que debería ir/ tiene que ir a la escuela.

e. Jodeme que puede pasarle eso a la oreja de un adulto/ podés ganar guita por desafinar

Paralelamente, otros ejemplos con jodeme/me jodés que analizados a lo largo de este trabajo (que repetimos en (46)) tampoco podrían ser parafraseados con no va que, como se observa en (47):

(46) a. Tugendhat House -me jodés que esto es de 1928!!

b. Jodeme que estos son mis padres??

c. Me jodés que tiene Twitter/ 51 años!

d. Jodeme que está de rojo.

e. Jodeme que sabe firmar!

(47) a. Tugendhat House -*no va que esto es de 1928!! 
b. *No va que estos son mis padres??

c. *No va que tiene Twitter/ 51 años!

d. *No va que está de rojo.

e. $*$ No va que sabe firmar!

Estos contrastes sugieren que no va que tiene una distribución gramatical más acotada que jodeme/me jodés que, por lo que las expresiones no pueden alternar en todos los contextos, pese a que transmiten un significado muy semejante ligado a la sorpresa. Como se sugiere en Kornfeld (2018, 2019), no va que se usa únicamente en narraciones (y por eso el verbo en presente se interpreta como un presente histórico, como ya comentamos), por lo que resulta incompatible con estados cuando estos se ligan a situaciones evaluativas o de comentario (como muestra (47)), mientras que sí puede aparecer con estados si estos tienen un carácter narrativo, como ejemplifica (41.c). Esto puede atribuirse al hecho de que no va que supone que el evento descripto en la cláusula principal es una 'información nueva' (rasgo e de Aikhenvald) o 'contraria a las expectativas' (rasgo c), que causa 'sorpresa' (rasgo b) a una 'mente no preparada' (rasgo d), pero no puede expresar que se trate de un 'descubrimiento súbito' (rasgo a). ${ }^{14}$

En cambio, jodeme/ me jodés que denota que el hablante acaba de descubrir que cierto hecho ocurrió, ocurre u ocurrirá. Ese 'descubrimiento súbito' presupone también el resto de los

${ }^{14}$ Es decir, no va que sería mirativo desde el punto de vista de Aikhenvald, ya que expresa sus rasgos semánticos (b-e), aunque no desde el de Mexas (2016) o Lau y Rooryck (2017), quienes privilegian la evidencialidad a partir del rasgo a. 
rasgos mirativos señalados por Aikhenvald: ante esa 'información nueva', el hablante expresa su 'sorpresa' enfática, ya que se trata de un hecho 'contrario a las expectativas' para una 'mente no preparada'. Por eso, jodeme/ me jodés que puede modificar no solo enunciados narrativos, sino también enunciados evaluativos o comentarios (i.e., ligados directamente con el acto de enunciación); el evento ante el que se expresa sorpresa se da por cierto independientemente del tiempo (pasado, presente o futuro), y además puede ser un evento "modalizado", e.g., una posibilidad o una obligación. ${ }^{15}$

Ahora bien, como contraparte, no es posible parafrasear con jodeme/me jodés que algunos de los ejemplos con no va que expuestos previamente, en particular aquellos enunciados narrativos en los que interviene la primera persona del singular o del plural, como (41.a-c) y (43.b), reproducidos en (48):

(48) a. No va que una vez que bajamos la barranca y nos sentamos al lado del río vimos salir del agua unos animalitos de lo más raros (Juan José Saer, El limonero real)

b. No va que hoy fui a la mañana a la verdulería y me encontré con Ribet, el maquinista de turno... (M. Laura Santos, Haya)

c. esta tarada no va que estamos saliendo del supermercado y se le cae de adentro del spencer el acondicionador (José M. Muscari, “Cotillón”)

15 En Kornfeld (2019) afirmábamos que la imposibilidad de no va que de coaparecer con perífrasis modales epistémicas con poder se debe a que la verdad del evento denotado por la proposición principal no puede ser puesta en duda. Dada la discusión en este trabajo, eso es, indudablemente, un error, ya que jodeme/ me jodés que también asume la (absoluta) verdad del evento de la cláusula principal, pero admite las variantes modales. 
(49) a. *Jodeme/ me jodés que una vez que bajamos la barranca y nos sentamos al lado del río vimos salir del agua unos animalitos de lo más raros

b. *Jodeme/ me jodés que hoy fui a la mañana a la verdulería y me encontré con Ribet

c. esta tarada $*$ jodeme/ me jodés que estamos saliendo del supermercado y se le cae de adentro del spencer el acondicionador

Las restricciones con la primera persona de (49) pueden ser ligadas a los valores gramaticales denotados por el clítico me, que remite deícticamente al acto de enunciación. Eso coopera en la interpretación evidencial de la expresión, que presupone que el evento acaba de ser descubierto por el hablante, lo que vuelve extraño que se vea focalizado un evento pasado que involucre al propio hablante, como sucede en los ejemplos de (49). No se trata, sin embargo, de una incompatibilidad formal con la primera persona, ya que, de hecho, jodeme/ me jodés que puede coaparecer con la primera persona (singular o plural) en ciertos contextos semántico-pragmáticos en el que el evento en realidad recae sobre otro participante distinto. Así, los siguientes ejemplos parecen expresar la constatación tardía de que los otros no advirtieron el hecho (50.a) o de que (el hablante y otros) pudieron molestar a Vivi (50.b) (cfr. también (17.a) y (31.c)):

(50) a. Jodeme que soy el único que se dio cuenta.

b. Me jodés que pudimos molestar tanto a Vivi.

Es distinto el estatuto de la segunda persona de confianza en singular del verbo en jodeme/ me jodés. En contextos dialógicos, 
se observa una total compatibilidad de la expresión con la segunda persona en segmentos narrativos o evaluativos, con interpretaciones personales (cfr. (20.c), (23.b-c), (30-d)) o genéricas (cfr. (24.a), (26.b)) (de hecho, los ejemplos de (49) no presentarían problemas si los verbos estuvieran en segunda persona). Sin embargo, no está claro que las propiedades personales de la flexión verbal sean realmente visibles: así, en la cláusula principal pueden aparecer otras segundas personas, sea del plural (51.a-b) o de respeto (51.c), lo que presupondría una "falta de concordancia" problemática si la flexión verbal de jodeme/ me jodés estuviera activa:

(51) a. Jodeme que ustedes también tienen uno que gime mientras juega?! Ajajajja

b. me jodes que ustedes fueron a la fiesta de disfraces.

c. -Naa, jodeme que usted también va a Pinamar.

Además, jodeme y me jodés aparecen en contextos claramente no dialógicos; por ejemplo, tuits sin un destinatario particular, como sucede, de hecho, en todos los ejemplos de (46). Estos datos sugieren que la segunda persona del singular en el verbo no está activa, sino que es, más bien, expletiva, lo que se comprueba también con otros marcadores de modalidad gramaticalizados, como dale, metele, ponele (cfr. Kornfeld, 2016).

Pasemos ahora a la comparación de jodeme/ me jodés que con el habia sido (que) del español de la región guaranítica. Según establece Avellana (2012), habia sido (que) es una construcción completamente cristalizada (sin ninguna posibilidad de variación en el verbo), en que el pretérito pluscuamperfecto ha perdido por completo el valor anafórico de anterioridad en el pasado que 
tiene en español general para expresar centralmente el significado de percepción demorada del evento descripto en la cláusula principal (i.e., el rasgo a de Aikhenvald), con interpretaciones secundarias de sorpresa por una información nueva contraria a la expectativas de una mente no preparada (i.e., rasgos b-e). Este conjunto de significados surge en la construcción presumiblemente por asociación con la partícula mirativa del guaraní ra'e, con la que a menudo coaparece, como muestra (52):

(52) a. Había sido Aquiles era el problema ra'e.

b. Había sido que a un ganadero francés lo "suicidaron" ra'e... (ejemplos de Avellana, 2012)

Recordemos que, según Avellana, habia sido (que) se combina en la cláusula principal con verbos en todas las personas del paradigma en distintos tiempos y aspectos (presente, pretérito perfecto e imperfecto y diversas perífrasis) y es compatible con todas las clases de aspectualidad: estados (53.a-c), actividades (53.d), realizaciones (53.e) y logros (53.f-g):

(53) a. Había sido tenía una novia bien guardadita.

b. Había sido que tenés corazón.

c. Había sido que los legisladores son maravillosos.

d. El trabajador del volante había sido estuvo laburando toda la noche

e. Había sido que todavía no almorcé... I love my job!

f. Por errores del sistema no se pudo cargar había sido el número gratis. 
g. A todos nos pasa había sido esto. (ejemplos de Avellana, 2012)

Como se observa en (53), además, habia sido (que) registra una gran movilidad: puede aparecer al principio (con o sin que), en el medio o al final de la cláusula, lo que demuestra el extremo grado de gramaticalización de la construcción, tal como destaca Avellana.

Agregamos a la información previa, el dato de que habia sido (que) puede ser combinado también con perífrasis de futuro (54.a), deónticas (54.b-c) y epistémicas (54.d-e), aunque tampoco se lo registra en subjuntivo o condicional (54.f-g), tal como no va que en (44.b-c) o me jodés/ jodeme que en (45.a-b):

(54) a. Había sido que vamos a ir a Europa en las vacaciones.

b. Había sido que tenés que hacer ayuno por 12 horas para hacerte un análisis de sangre.

c. había sido que hay que pedir permiso hasta para que te guste lo que se te canta el ojete.

d. Había sido que podemos usarlo para producir abrigos/ ser un país serio.

e. Había sido que puede haber controles de rigor.

f. *Había sido que fuera/ vaya a la escuela.

g. ?? Había sido que Julia sería el amor de su vida

Si bien coinciden en expresar los rasgos (a-e) de Aikhenvald, una diferencia significativa entre jodeme/ me jodés que y babia sido (que) se refiere a las personas que pueden aparecer en la cláusula 
principal. Me jodés/ jodeme (que) no se combina normalmente con verbos en primera persona en secuencias narrativas que refieran a eventos del pasado que le ocurrieron al hablante, como ya dijimos para (49), contextos en los que habia sido (que) puede aparecer sin ningún problema, como demuestran (55.a-c). Otras oraciones recopiladas con babia sido (que) en combinación con la primera persona del singular (como (55.d-e)) tampoco serían emulables con jodeme/ me jodés (cfr. (56)):

(55) a. Había sido que una vez que bajamos la barranca y nos sentamos al lado del río vimos salir del agua unos animalitos de lo más raros (cfr. 48-9.a)

b. Había sido que hoy fui a la mañana a la verdulería y me encontré con Ribet, el maquinista de turno... (cfr. 48-9.b)

c. esta tarada había sido estamos saliendo del supermercado y se le cae de adentro del spencer el acondicionador (cfr. 48-9.c)

d. Había sido que todavía no almorcé ...I love my job!

e. Yo [es] toy había sido pero apenitas se me ve.

(56) a. *Jodeme que todavía no almorcé ...I love my job!

b. *Me jodés que yo [es]toy pero apenitas se me ve.

Los datos de (56), como los de (49), pueden atribuirse a que, con jodeme/ me jodés que quien percibe tardía o súbitamente el evento siempre es el hablante, provocando que sea extraña la aparición de un evento pasado en la primera persona. En cambio, con habia sido (que) el 'descubrimiento súbito' puede referir al hablante, al oyente o a un personaje de la narración, tal como menciona Aikhenvald. 
En el mismo sentido, había sido (que) y jodeme/ me jodés que difieren fundamentalmente en su relación con el momento de habla, en particular en lo que hace al llamado tiempo de adquisición de la evidencia (o TAE). En el caso del había sido (que), el tiempo de adquisición de la evidencia es variable: puede ser presente o pasado (cfr. Carol y Avellana, 2019), mientras que con me jodés/ jodeme que el TAE solo puede ser presente, es decir, solo se puede expresar que el hablante se acaba de dar cuenta del hecho. Así, vale la pena contrastar el ejemplo de (57.a) con la probable contraparte con jodemel me jodés que: (57.a) invariablemente remite al descubrimiento por parte del hablante en tiempo presente, mientras que (57.b) sería válido si el hablante acaba de darse cuenta del hecho, pero también si un personaje (por ejemplo, Ulises) lo descubrió en el momento de la narración en pasado (en cuyo caso, es implausible que el hablante exprese sorpresa en el momento de la enunciación, como observan Carol y Avellana, 2019).

(57) a. Me jodés que Aquiles era el problema... (=40.a)

b. Había sido Aquiles era el problema ra'e. (Avellana, 2012)

Ese contraste se entrelaza con otra propiedad relevante que distingue las expresiones, que es la (im)posibilidad de aparecer en cláusulas subordinadas. Así, como destaca Avellana (2012), babia sido (que) puede aparecer en cláusulas completivas y relativas con el verbo principal anclado en el pasado (como muestra (58)), algo que es completamente imposible para jodeme/me jodés que (cfr. (59)): 
(58) a. Encontró que había sido un rayo partió el lapacho... (Melià et al., 1958, p. 140, citado por Avellana y Carol, 2019)

b. La confesión de la niña fue que había sido tenía contrato con la disco "Brunetto".

c. Cuando entré con él a una piecita, que había sido era prestada de otro... (Avellana, 2012)

(59) a. Encontró que *jodeme que un rayo partió el lapacho...

b. La confesión de la niña fue que *me jodés que tenía contrato con la disco "Brunetto".

c. Cuando entré con él a una piecita, que *jodeme que era prestada de otro...

Resaltemos que los casos en que habia sido (que) aparece en una proposición subordinada con un verbo principal con anclaje en el pasado, como (58), también son enunciados que no pueden expresar sorpresa, según puntualizan Carol y Avellana (2019), dado que el descubrimiento necesariamente tuvo lugar en un momento anterior al acto de habla, por lo que el hablante (o el participante involucrado) ya no se sorprende. Como contraparte, jodeme/ me jodés que siempre expresa sorpresa, dado que el 'descubrimiento súbito' debe ser entendido en tiempo presente, en relación directa con el acto de enunciación. 


\section{Conclusiones}

En este trabajo atendimos a las propiedades gramaticales y semánticas de la expresión del español rioplatense jodeme/ me jodés (que), que sirve para comunicar la sorpresa enfática del hablante frente a un hecho. Partimos para nuestro análisis de los significados y la distribución sintáctica de joder en tanto verbo léxico en el español rioplatense, con semejanzas y diferencias respecto de los usos generales del mismo verbo. Con ese punto de partida, establecimos en el apartado 3 los contextos sintácticos y semántico-pragmáticos relevantes desde donde se produce la formación de jodeme/ me jodés (que): un contexto dialógico de réplica, con las construcciones como respuesta autónoma, en un primer paso, y, en el segundo paso, con el agregado de una "proposición completiva", que incluye verbos principales con diversas categorías gramaticales asociadas (en tiempo y aspecto, aunque no en modo) y que pueden denotar distintos aspectos léxicos (o Aktionsart).

En el apartado 4, observamos que la distribución y las propiedades de jodeme/ me jodés que acarrean una deslexicalización del verbo joder (ya que podemos descartar su relexicalización, sea como verbo de sentimiento sea como verbo de decir), a lo que se suma una completa cristalización de las categorías morfológicas de clítico y verbo. Esas propiedades invitan a pensar a la expresión (en sus dos variantes) como un marcador de modalidad gramaticalizado, que se ubica en una posición periférica en la oración, por lo que la "proposición completiva" resulta ser en realidad la cláusula principal de la oración. 
Por último, en el apartado $\mathbf{5}$ nos hemos detenido en el contraste entre las propiedades gramaticales y semánticas de jodeme/ me jodés que y las de otros dos marcadores de modalidad gramaticalizados de significado semejante en el español de la Argentina, no va que y habia sido (que), ya tratadas en Kornfeld (2018, 2019). Este procedimiento contrastivo permitió iluminar las propiedades relevantes de las tres estructuras.

En particular, concluimos que la expresión del español rioplatense no va que solo puede expresar sorpresa enfática en narraciones (lo que explica sus mayores restricciones con tiempos y modos), y nunca se vincula con el 'descubrimiento súbito' (o rasgo a de Aikhenvald). En cambio, jodeme/ me jodés que expresa sorpresa enfática en distintos tipos de enunciados, que se vinculan deícticamente con el 'descubrimiento súbito' del evento por parte del hablante en el mismo momento de la enunciación (más allá de si el evento se ubica como pasado, presente o futuro). Esa dependencia de la perspectiva del hablante (señalada inequívocamente por el clítico me) hace que en ciertos contextos se vea restringida la aparición de la primera persona en los verbos principales (cfr. ejemplos de (49) o (55)), y que sea imposible la interpretación pasada del 'descubrimiento súbito' (en (57), por ejemplo). En contraste, en el había sido (que) del español guaranítico el 'descubrimiento súbito' puede manifestarse en cualquier persona (i.e., hablante, oyente o personaje principal) y en cualquier tiempo real (pasado o presente). Ello explica su distribución marcadamente más amplia, incluyendo las cláusulas subordinadas (cfr. (58-59)).

Las mayores restricciones de me jodés/ jodeme que respecto del 'descubrimiento súbito' pueden atribuirse a que su 
gramaticalización no se encuentra finalizada, algo esperable en la medida en que se trata de una expresión (muy) novedosa en español rioplatense. Solo el tiempo podrá decir si su destino es permanecer con los mismos valores semánticos o aumentar su grado de gramaticalización, perdiendo la relación inmediata con el acto enunciativo, o si, en cambio, deja de usarse, como ha ocurrido con tantas expresiones efímeras del lenguaje coloquial.

\section{Referencias Bibliográficas}

Aikhenvald, A. (2012). "The essence of mirativity". Linguistic Typology, 16, 435-485.

Avellana, A. (2012). El español de la Argentina en contacto con lenguas indígenas: un análisis de las categorías de Tiempo, Aspecto y Modo en el español en contacto con el guaraní, el toba (qom) y el quechua en la Argentina. Munich: LINCOM.

Carol, J. y Avellana, A. (2019). "Tiempo, evidencialidad y miratividad en guaraní paraguayo y español de contacto: ra’e y había sido". Verba, 46, 11-67.

Cinque, G. y Rizzi, L. (2016). "Functional Categories and Syntactic Theory". The Annual Review of Linguistics 2016, 2, 139-163.

Kornfeld, L. (2016). “Dale nomás... Misterios y revelaciones de un clásico argentino”. Filología, XLVI, 33-55.

---. (2018). "Y no va que se nos viene otra vez una época de aguaceros: sobre la sorpresa codificada en la gramática". Ignacio Bosque, Sylvia Costa y Marisa Malcuori (eds.) Palabras en lluvia minuciosa. Veinte visitas a la gramática del español 
en homenaje a Ángela Di Tullio. Madrid: Iberoamericana Vervuert, 205-220.

---. (2019). "Expresión de la sorpresa, miratividad y gramaticalización de verbos inacusativos en español". Borealis, Vol. 8 No 2 (2019): Monographic topic: The grammar of auxiliaries and periphrases, 165-197.

Lau, M. y Rooryck, J. (2017). "Aspect, evidentiality, and mirativity”. Lingua (Special Issue - Essays on Evidentiality), 110-119.

Mexas, H. (2016). Mirativity as realization marking: a crosslinguistic study. Tesis de maestría. Leiden: Universidad de Leiden.

Pujalte, M. y Zdrojewski, P. (2013). "Procesos de transitivización en el español del Río de la Plata”. Ángela Di Tullio (coord.) El español de la Argentina: estudios gramaticales. Eudeba: Buenos Aires, 129-149.

Salanova, A. y Carol, J. (2017). "The guarani mirative evidential and the decomposition of mirativity". Andrew Lamont y Katerina Tetzloff (eds.) Proceedings of the Forty-Seventh Annual Meeting of the North East Linguistic Society (NELS 47), volumen 3. Massachusetts: University of Massachusetts, 63-76.

\section{Fecha de recepción: 02/07/20}

Fecha de aceptación: 11/09/20 